INT. J. REMOTE SENSING, 1990, VOL. 11, NO. 12, 2185-2204

\title{
Remote sensing of coastal waters by airborne lidar and satellite radiometer
}

\section{Part 2: Measurements}

\author{
A. SCHMITZ-PEIFFER $\dagger$, T. VIEHOFF $\ddagger$ \\ Institut für Meereskunde, Abt. Meteorologie, \\ Düsternbrooker Weg 20, D-2300 Kiel 1, F.R. Germany \\ and H. GRABL \\ Max-Planck-Institut für Meteorologie, Bundesstr. 55, \\ D-2000 Hamburg 13, F.R. Germany
}

(Received 14 June 1989)

\begin{abstract}
Active and passive remote sensing techniques for measurement of oceanic constituents have been compared using the ADRIA'84 dataset. A new method has been developed to retrieve the amount of nonchlorophyllous particles by airborne lidar measurements at three wavelengths. If the lidar measurements of chlorophyll- $a$ and Gelbstoff are calibrated by in situ measurements, the fluorescence efficiencies can be estimated. Specific extinction coefficients for chlorophyll$a$ and nonchlorophyllous particles for the northern Adriatic Sea have been derived by comparing in situ and underwater irradiance measurements with radiative transfer calculations, using the ocean-atmosphere model by Fischer (1983). For the Coastal Zone Colour Scanner (CZCS), an algorithm for chlorophyll-a measurements was derived. The comparison with chlorophyll- $a$ lidar measurements shows that different scales are resolved by both instruments. The CZCSchlorophyll- $a$ concentrations are influenced by Gelbstoff and nonchlorophyllous particles. It is possible to use airborne lidar measurements of chlorophyll- $a$ for calibrating spaceborne radiometers, if the fluorescence efficiency of chlorophyll- $a$ is known and if the lidar itself is calibrated. The comparison between Advanced Very High Resolution Radiometer (AVHRR) sea surface temperatures and CZCS measurements indicates that mesoscale structures in the ocean are much better indicated by measurements in the visible spectrum. Mesoscale structures are often masked by the warming of the ocean top layer when measuring in the infrared.
\end{abstract}

\section{Introduction}

Due to high pollution of coastal waters with the danger of a break-down of the biological balance (see the extreme plankton blooming and the death of thousands of seals in the North Sea in summer 1988), intense activities to stop pollution are necessary and a monitoring system working operationally detecting ocean pollutants is urgently needed. Active and passive remote sensing techniques, measuring the colour of the sea water at different wavelengths are able to detect all those oceanic

Present addresses: † Unternehmensbereich Kommunikationssystem und Antriebe, MBBOttobrunn, D-8000 München 80, P.O. Box 801169 Abt. KL-31, F.R. Germany. $\ddagger$ Alfred-Wegener Institut für Polar-und Meeresforschung, D-2850 Bremerhaven, Am Handelshafen 12, Abt. Ozeanographie, F.R. Germany. 
substances, which influence the light backscattered by sea water. While passive systems work or have been working operationally like the Coastal Zone Colour Scanner (CZCS) on Nimbus-7 or the Thematic Mapper (TM) on Landsat-4 and -5, active systems like an airborne lidar up to now have only been used during specific experiments, e.g. for oil detection (Diebel-Langohr et al. 1985) or for the detection of oceanic fronts (Diebel-Langohr et al. 1986). Theoretical studies have shown, that three oceanic substances can be derived from passive systems measuring at several wavelengths (Fischer et al. 1986). High spectral resolution measurements including the sun-induced chlorophyll- $a$ fluorescence from an airplane (Gower 1981) and theoretical studies, which have shown the possibility to detect this fluorescence even from space (Schlüssel and Graßl 1984), were first steps to new passive spaceborne techniques.

An airborne lidar system offers the possibility to detect chlorophyll- $a$ (chl-a) and Gelbstoff (GS) with high accuracy (Schmitz-Peiffer and Graßl 1990) and might be used for the calibration of passive systems. In this paper active and passive measurements from ships, platforms, airplanes and satellite during the ADRIA'84 experiment (Schlittenhardt 1986) have been evaluated and compared in order to answer the following questions:

(1) The circumstances under which may three classes of oceanic substances be derived from lidar measurements.

(2) Whether our radiative transfer models adequately describe radiative transfer in coastal waters.

(3) If airborne lidar measurements be used to calibrate passive satellite sensors.

In this paper a new method for extracting the amount of nonchlorophyllous particles (NCP) by lidar will be introduced. As a first step we use concentration and specific extinction of chl- $a$, NCP and GS as input parameters for the radiative transfer model whose results form a basis for a comparison with CZCS measurements. Then lidar and CZCS measurements are also compared.

After a very short description of the used radiative transfer models for sunlight and laserlight; $\$ 3$ describes the calibration of the active and passive sensor calibration of the active and passive sensor calibration by in situ measurements before $\S 4$ discusses the results.

\section{Radiative transfer models}

For modelling the radiative transfer of laser light, the lidar equations for Raman and fluorescence scattering Browell 1977), considering multiple scattering by an approach by Gordon (1982) have been used as described in part 1 of this paper. The radiation transfer to a passive radiometer measuring the backscattered sunlight from the ocean and the atmosphere is simulated by an ocean-atmosphere model based on the matrix-operator method (Fischer and Graßl 1984). The input data for both models have been described in more detail in part 1 (Schmitz-Peiffer and Graßl 1990).

\section{Measurements}

3.1. Hydrographic situation of the northern Adriatic Sea and the ADRIA'84 experiment

The general circulation in the Adriatic Sea can best be described as a cyclonic gyre with northward component along the Yugoslavian coast and a return flow along the Italian coast. In summer the northern part is characterized by a strong stratification, partly maintained by the freshwater input from the Italian rivers at the north-western 
part of the Adriatic Sea, forming a thin surface layer of 5-10 $\mathrm{m}$ with fresh, warm water overlying a relatively warm, however colder salty bottom layer $(<50 \mathrm{~m})$ (Barale et al. 1984).

The Italian-German remote sensing experiment ADRIA'84 took place in the northern Adriatic Sea from 23 August until 7 September 1984. The aim of the experiment was a better understanding of dynamical processes in this area with the help of in situ measurements, remote sensing and model calculations (Schlittenhardt 1986). Main emphasis was given to the airborne lidar and radiometric measurement from satellites, as both methods resolve different scales of eddy structures. The experiment was located in the northwest corner of Adriatic Sea $\left(44^{\circ} 30^{\prime}-45^{\circ} 30^{\prime} \mathrm{N}\right.$, $12^{\circ} 20^{\prime}-13^{\circ} 15^{\prime} \mathrm{E}$ ), an area of $150 \mathrm{~km} \times 90 \mathrm{~km}$. The northern Adriatic Sea is the shallowest area and one of most polluted waters of the Mediterranean Sea. Large river runoff, extended lagoon systems and the seasonal heat exchange at the surface give rise to relative high levels and gradients of phytoplankton. The lagoon systems and the rivers, as well as the water drained from heavily cultivated surrounding land, are responsible for pollutants in these regions (Schlittenhardt 1986).

Figures 1 and 2 show isolines of mean surface concentration of chl- $a$ and GS,

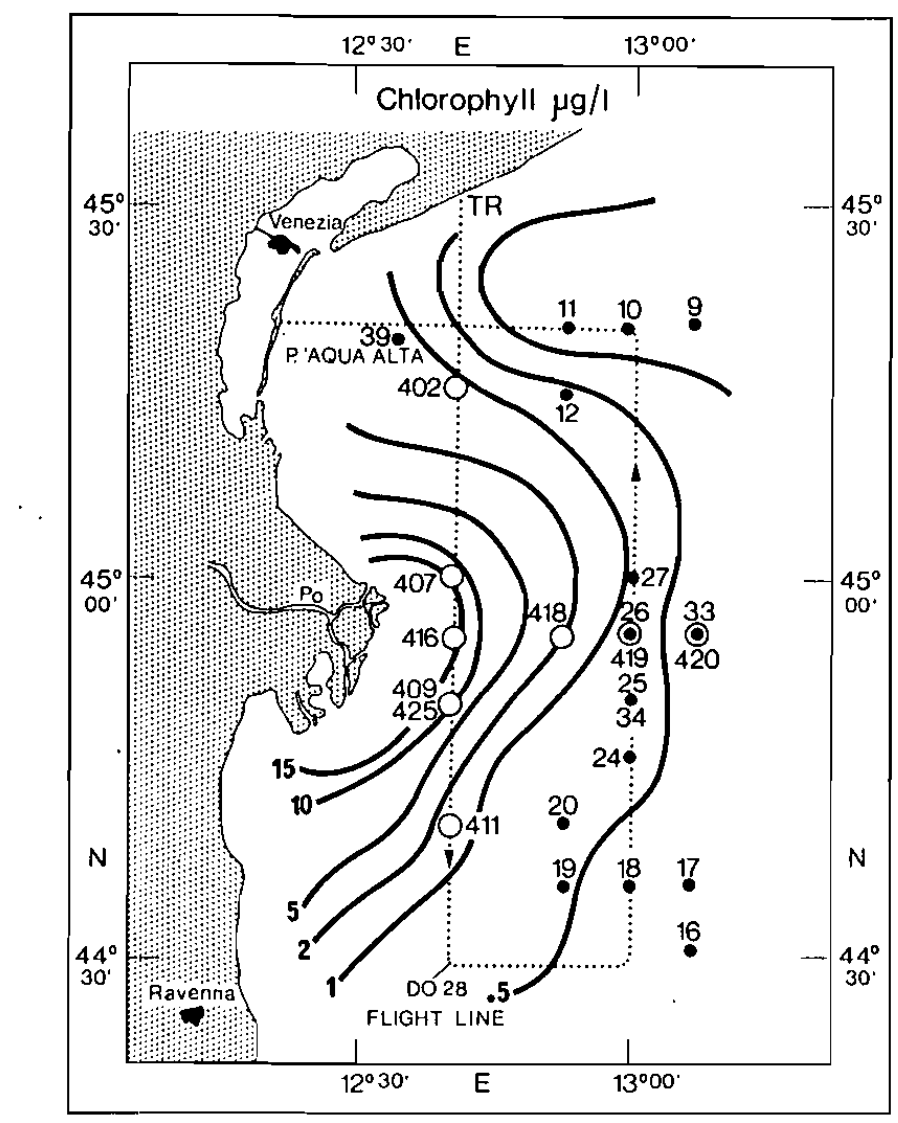

Figure 1. ADRIA'84: mean chl- $a$ density in $\mu \mathrm{g} / 1$ during the experiment (28 August1 September) using more than 120 in situ measurements from ships and platforms. The dotted line represents the flight track of the airborne lidar. TR, western track used for comparison of lidar and CZCS. Numbered stations indicate measurements with underwater radiometer by RV Umberto d'Ancona $(O)$ and by RV Bannock $(\bullet)$. 


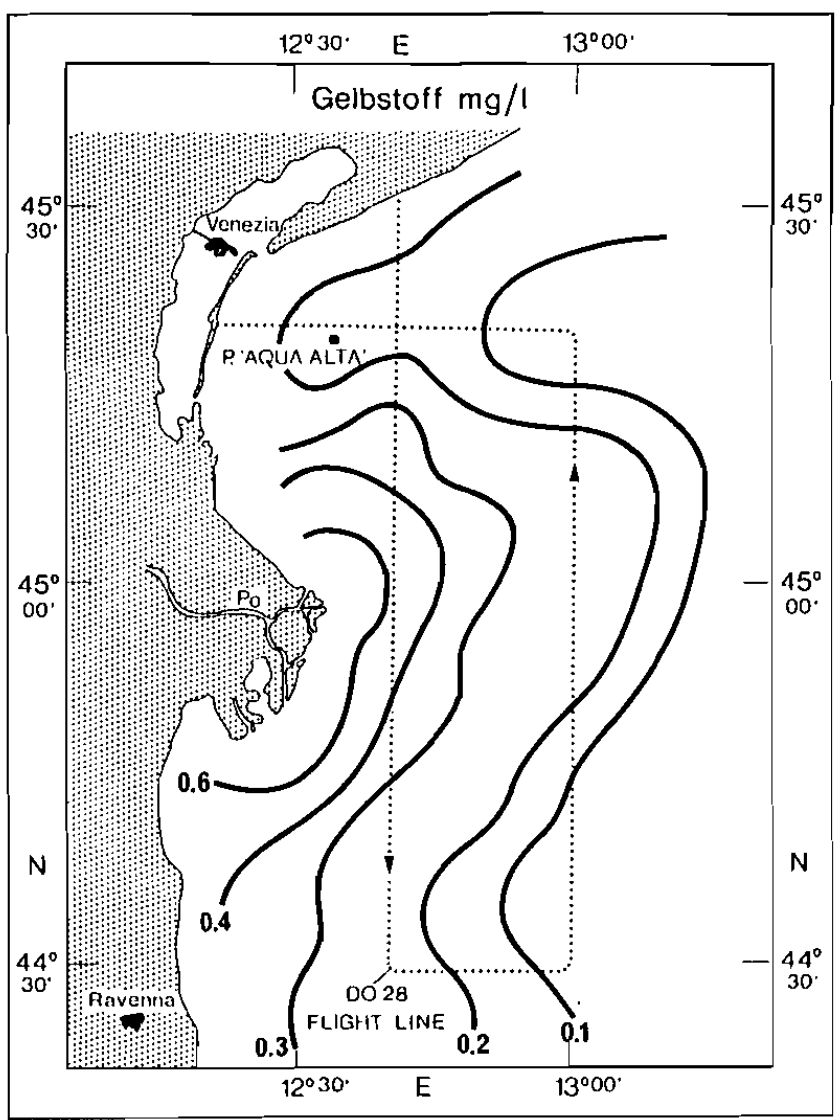

Figure '2. ADRIA'84: mean GS density in $\mathrm{mg} / \mathrm{l}$ during the experiment (28 August1 September) using more than 120 in situ measurements from ships and platforms (see figure 1 for details).

which have been derived from more than 120 measurements during the five main days of the experiment (28 August-1 September 1984). In figure 3 the total amount of suspended matter or seston is shown. It is named NCP here, as the chl- $a$ portion is negligible compared to the total amount. The chl- $a$ data are bimodally distributed. Most data are from rather clear waters with chl- $a$ concentrations below $3 \mu \mathrm{g} / \mathrm{l}$. There exists no station with concentrations between 5 and $13 \mu \mathrm{g} / \mathrm{l}$ while two stations have concentrations above $13 \mu \mathrm{g} / \mathrm{l}$. The GS-data are uniformly distributed between 0.1 and $0.6 \mu \mathrm{g} / \mathrm{l}$. Figures 1 to 3 show that all measured substances have their maximum concentration near the mouth of the River Po and are highly correlated. The strong influence of the River Po on the northern Adriatic Sea is also seen from the depth resolved profiles. The maximum concentration of all substances reaches down to a depth of $5 \mathrm{~m}$ and then rapidly decreases to a depth of $10 \mathrm{~m}$. Typical values for chl- $a$ at the surface in the River Po are $15 \mu \mathrm{g} / \mathrm{l}$ decreasing to $10 \mu \mathrm{g} / 1 \mathrm{at} 5 \mathrm{~m}$. The low salinity in the fresh water in the Po delta increases from $22 \%$ at the surface to $32 \%$ at a depth of $10 \mathrm{~m}$ causing a very stable stratification.

In the eastern part all substances are vertically homogeneous down to $10 \mathrm{~m}$. The 


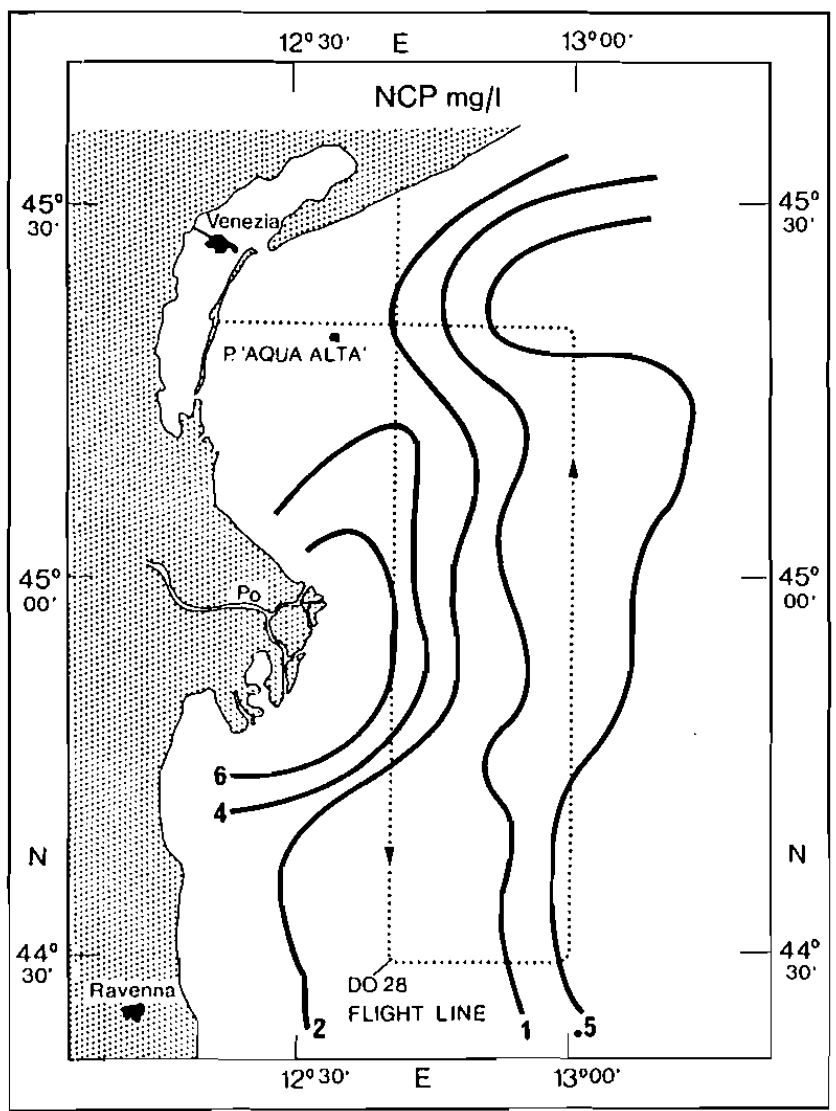

Figure 3. ADRIA'84: mean NCP density in $\mathrm{mg} / \mathrm{l}$ during the experiment (28 August1 September) using more than 120 in situ measurements from ships and platforms (see figure 1 for details).

salinity is about $34 \%$. A phytoplankton maximum near the thermocline in $20 \mathrm{~m}$ depth could not be detected by the radiometric measurements. The mean horizontal distribution of oceanic substances masks the large temporal variability near the River Po delta. Several ship measurements along the western flight track (TR) during the experiment show daily variations, e.g. of $\pm 5 \mu \mathrm{g} / \mathrm{l} \mathrm{chl}-a$ at the same gridpoint. Reasons for this variability might be unregular discharge of the River Po due to changes in advection and turbulence, natural phytoplankton population and density fluctions or errors in the extraction methods for the substances. The biological chl-a extraction methods lead to errors of \pm 30 per cent (Maske, personal communication, 1986). The error is increased by the heterogeneity of the distribution around the ship.

\subsection{Intercomparison of active and passive measurements}

For a comparison three steps are necessary: (a) in situ measurements of the oceanic substances; (b) measurements by the Airborne Oceanic Lidar System of the University of Oldenburg (OLS) and lidar model calculations; and (c) measurements 
by passive instruments from ships and satellite (EOS-underwater-radiometer, CZCS) and model calculations.

The steps for this comparison are shortly explained: The in situ measurements of chl- $a$, GS and NCP are the input parameters for the radiative transfer model. This model is calibrated with the reflectances measured by the underwater radiometer, to calculate specific extinction coefficients for chl- $a$ and NCP. Using the specific extinction of chl- $a$, GS and NCP and the lidar measurements of chl- $a$ and GS, the lidar model is calibrated to determine the amount of NCP from the lidar data. The lidar measurements of chl- $a$, GS and NCP, now available for all flight tracks, are also used as input parameters for the radiative transfer model, which simulates the radiation measurements of the CZCS. Finally the results of the radiative transfer model and the lidar measurements are compared with the CZCS measurements.

\section{Results}

4.1. Calculation of the specific extinction coefficients for chl-a and NCP

The irradiances measured by the underwater radiometers onboard the participating ships are compared with model calculations to determine the specific extinction coefficients of chl- $a$ and NCP. For GS the specific extinction is fixed to $c_{\mathrm{GS}}=0.212 \mathrm{~m}^{-1} /\left(\mathrm{mg} / \mathrm{m}^{3}\right)$ at $\lambda=450 \mathrm{~nm}$, a mean value from measurements in different waters (Hojerslev 1979).

The underwater radiometers measure down- and upwelling irradiances $E_{\mathrm{d}}$ and $E_{\mathrm{u}}$ at the four CZCS channels $443,520,550$ and $670 \mathrm{~nm}$. Irradiance measurements in general were performed from 10.00 to $16.00 \mathrm{~h}$ local time down to a depth of $10 \mathrm{~m}$. From these measurements, reflectances $R=E_{\mathrm{u}} / E_{\mathrm{d}}$ and diffuse extinction coefficients $K_{\mathrm{d}}=-\delta \ln E_{\mathrm{d}} / \delta z$, respectively $K_{\mathrm{u}}=-\delta \ln E_{\mathrm{u}} / \delta z$, were calculated. Measurements were made 24 grid points together with in situ ship measurements of chl- $a$, GS and NCP (for more details see Schmitz-Peiffer 1986). The concentrations of chl- $a$, GS and NCP are the input data of the radiative transfer model. From the diffuse extinction coefficients the mean penetration depth of the radiometric signal was estimated and the specific concentrations were averaged arithmetrical above this depth. This is not critical as due to the high turbidity of the area in the River Po delta only surface concentrations are detected, while on the eastern side of the experiment area with clearer water the substances are distributed vertically homogeneous above the thermocline.

Figure 4 compares measured and calculated reflectance values using the following specific extinction coefficients for chl- $a\left(c_{\mathrm{p}}\right.$ and for NCP $\left(c_{\mathrm{N}}\right)$ at $\lambda=565 \mathrm{~nm}$ as input parameters for the radiative transfer model:

$$
c_{\mathrm{p}}=0.077 \mathrm{~m}^{-1} /(\mu \mathrm{g} / \mathrm{l})
$$

and

$$
c_{\mathrm{N}}=0.3 \mathrm{~m}^{-1} /\left(\mathrm{mg} / \mathrm{m}^{3}\right)
$$

Two water types can easily be distinguished in figure 4 . Stations belonging to group I are located in regions with low concentrations of oceanic substances. At these stations the transmission is higher in the blue than in the green part of the spectrum. The numbering of the stations is as in figure 1 .

For group II the situation is opposite: chl- $a$ and GS astrongly absorb the light in the blue part of the spectrum while NCP and chl- $a$ lead to comparably high transmission at $550 \mathrm{~nm}$ due to their reduced absorption. Group II stations belong to 

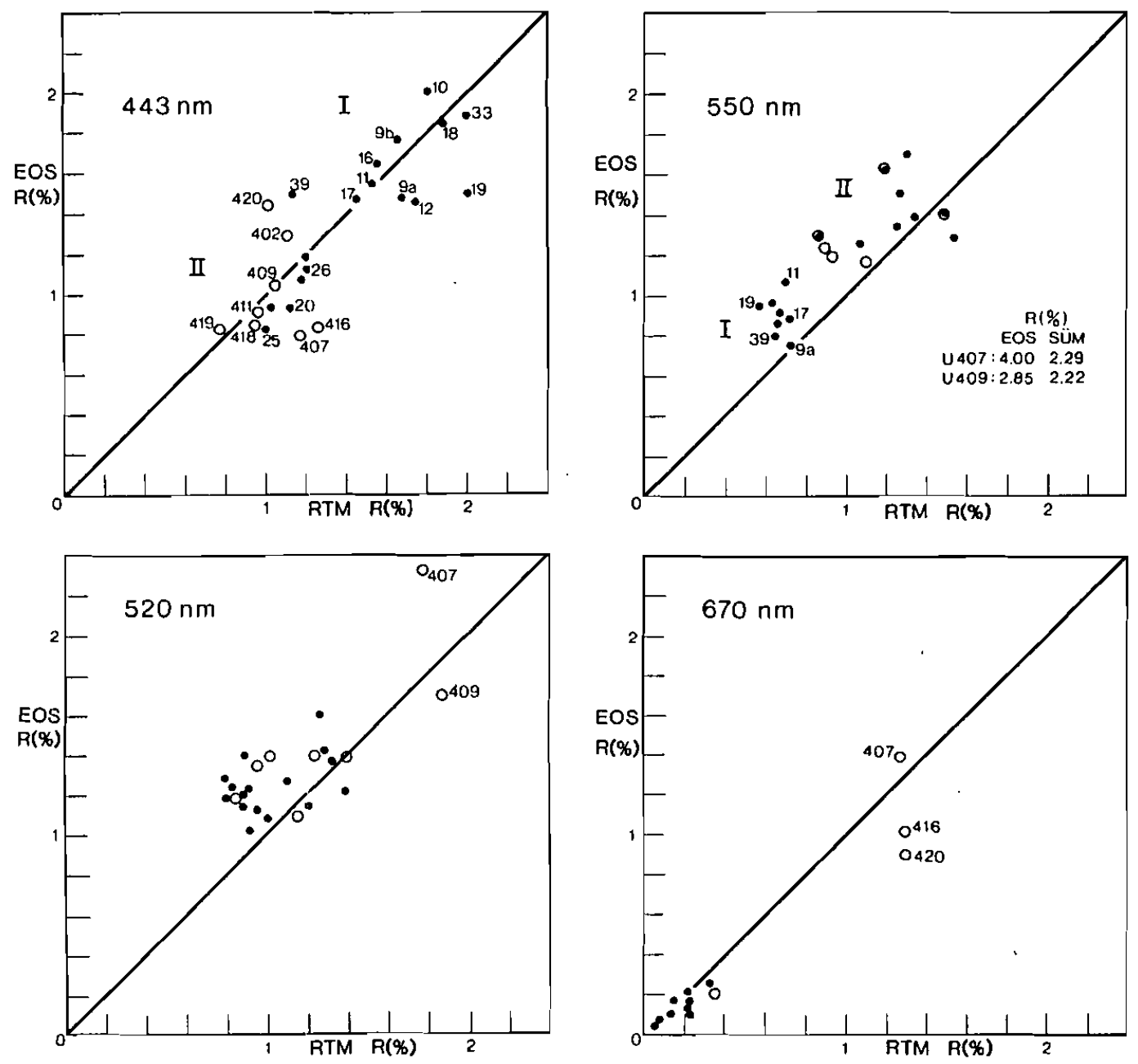

Figure 4. Comparison of the measured (underwater radiometer (EOS)) and calculated reflectance (RTM) for 4 CZCS channels just below the water surface. Input data for the radiative transfer model are in situ measurements of chl-a, GS and NCP concentrations taken simultaneously with the radiometric measurements from RV Umberto d'Ancona $(O)$ and RV Bannock (๑).

the River Po plume. At $\lambda=520 \mathrm{~nm}$, absorption and scattering processes balance each other and the reflectance values of both groups are similar. Hence it is not possible to distinguish between the two groups at this wavelength. At $\lambda=670 \mathrm{~nm}$ only a few data are available, as in this part of the spectrum the rather high water absorption reduces the signal at the detector.

In the green part of the spectrum, the reflectances calculated by the calibrated model are smaller than the measured reflectances. The model adaptation could be improved by further changes of optical parameters like the single scattering albedo of chl- $a$ and of NCP. To keep the calibration of the optical parameters simple and thus clear, only the specific extinction coefficients of chl- $a$ and NCP have been adjusted. 


\subsection{Calibration of the lidar measurements}

The airborne oceanographic lidar of the University of Oldenburg (OLS) uses a pulsed excimer and dye laser for excitation. The detection wavelengths during ADRIA' 84 were $344 \mathrm{~nm}, 380 \mathrm{~nm}, 500 \mathrm{~nm}, 533 \mathrm{~nm}, 650 \mathrm{~nm}$ and $685 \mathrm{~nm}$. For each pulse the signals at three wavelengths were measured. The different wavelength combinations per shot are called 'modes' (Diebel-Langenohr et al. 1986). The table gives an overview over the five used modes. During the flights all five modes were used alternatingly. In modes 1,2 and 5 the excimer laser is used. For example, using mode 1, the Raman-scattering at $344 \mathrm{~nm}(\mathrm{R})$ and the GS fluorescence at 366 and $380 \mathrm{~nm}$ are measured (G). From table 1 it is obvious that the modes have been chosen especially for the detection of different kinds of GS, which can be classified due to their different fluorescence spectra.

The present data are mean values of three lasershots per mode. A mean value corresponds to a horizontal resolution of $250 \mathrm{~m}$. The signals are depth integrated. On three days during the experiment (29-31 August 1984) from 10.00 to 14.30 local time, airborne measurements from $200 \mathrm{~m}$ height were performed. The detected depth integrated chl- $a$ and GS-signals for the wavelengths $308 \mathrm{~nm}$ (mode 1) and $451 \mathrm{~nm}$ (mode 4) are normalized with the corresponding Raman-signals at 344 and $533 \mathrm{~nm}$.

Due to the spectrally broad GS fluorescence background, the Raman-signal is increased at 344 and $533 \mathrm{~nm}$, which leads to an underestimation of the normalized fluorescence signals. The Raman-signal at $344 \mathrm{~nm}$ is located on the shortwave shoulder of the GS-fluorescence at $380 \mathrm{~nm}$. With a linear baseline fixed at 380 and $366 \mathrm{~nm}$, the GS-background can be eliminated and hence the Raman-signal corrected. At $533 \mathrm{~nm}$ the Raman-signal is located near to the maximum of the GS-fluorescence, which is about 1.25 times higher at $500 \mathrm{~nm}$ (Diebel-Langohr et al. 1986). This background signal is subtracted from the measured Raman-signal. At 39 stations along the flight track during the three days with lidar overflights, in situ measurements of the oceanic substances in one or more depths were available. However, only six of the 39 ship-measurements have been made simultaneously with the lidar measurements. Other in situ measurements differ by less than $\pm 4 \mathrm{~h}$ from the flight time. As they do not show any systematic deviation in the calibration line with the lidar data, they are also considered useful. Concentrations were calculated as explained in $\S 4.1$.

Using the in situ measurements, the relation between the Raman-corrected fluorescence signal $\left(P_{\mathrm{fn}}\right)$ and the chl- $a$ concentration is

$$
\operatorname{chl}-a(\mu \mathrm{g} / \mathrm{l})=(10.8 \mu \mathrm{g} / \mathrm{l}) \pm 1.0 \mu \mathrm{g} / \mathrm{l}) P_{\mathrm{fn}}
$$

Measurement modes of the OLS during ADRIA'84 with corresponding excitation and detection wavelengths. R, Raman signal: GS, Gelbstoff fluorescence; chl- $a$, chl- $a$ fluorescence. For more details see text.

\begin{tabular}{cccll}
\hline Mode & $\lambda_{1}$ & \multicolumn{1}{c}{$\lambda_{\mathrm{d}}$} & \multicolumn{1}{c}{$\lambda_{\mathrm{d}}$} & \multicolumn{1}{c}{$\lambda_{\mathrm{d}}$} \\
\hline 1 & 308 & $344(\mathrm{R})$ & $366(\mathrm{GS})$ & $380(\mathrm{GS})$ \\
2 & 308 & $500(\mathrm{GS})$ & $533(\mathrm{GS})$ & $650(\mathrm{GS})$ \\
3 & 451 & $500(\mathrm{GS})$ & $533(\mathrm{R})$ & $650(\mathrm{GS})$ \\
4 & 451 & $500(\mathrm{GS})$ & $533(\mathrm{R})$ & $685(\mathrm{chl}-a)$ \\
5 & 308 & $533(\mathrm{GS})$ & $650(\mathrm{GS})$ & $685(\mathrm{chl}-a)$ \\
\hline
\end{tabular}




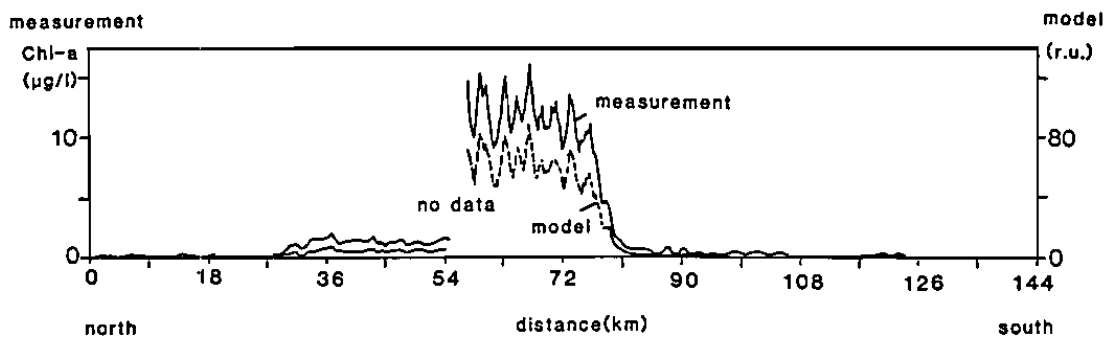

(a)

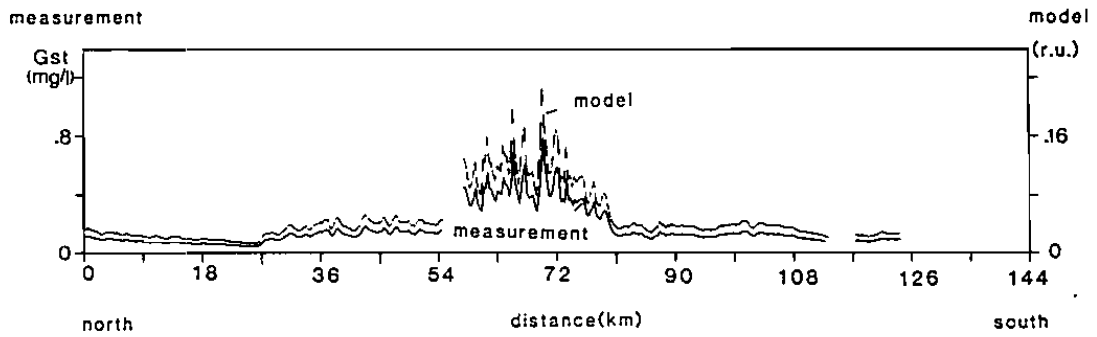

(b)

Figure 5. (a) Chl-a, measured by lidar on flight track TR in north-south direction (solid line) and chl- $a$ calculated with the lidar model not yet calibrated with the measurements (broken line). Flight M60; date: 31 August 1984; time: $12.00 \mathrm{~h}, \lambda_{1}=451 \mathrm{~nm}$. The chl-a signals at $685 \mathrm{~nm}$ are normalized with the Raman signal at $533 \mathrm{~nm}$. (b) As $(a)$ but for GS fluorescence, measured at $500 \mathrm{~nm}$ and normalized with the Raman signal at $533 \mathrm{~nm}$.

with a variance $r^{2}=0.85$, at a significance level of 95 per cent. The relation between the GS-fluorescence signal $P_{\mathrm{Gn}}$ and the Gs concentration (GS) is:

$$
\mathrm{GS}(\mathrm{mg} / \mathrm{l})=(1.5 \mathrm{mg} / 1 \pm 0.1 \mathrm{mg} / \mathrm{l}) P_{\mathrm{Gn}}
$$

with $r^{2}=0.83$ at a significance level of 95 per cent. $\left(P_{\mathrm{fn}}\right.$ and $P_{\mathrm{Gn}}$ are given in relative units.) The calibrated lidar measurements for the western flight line TR on 31 August 1984 are displayed in figures $5(a)$ and $5(b)$ (solid line). chl- $a$ and GS reach their maxima with concentrations above $10 \mu \mathrm{g} / \mathrm{l}$ and $0.4 \mathrm{mg} / \mathrm{l}$ respectively in the River Po delta between kilometres 60 and 70 . The dotted line marks a lidar model calculation under consideration of all three substances chl- $a$, GS and NCP. The model in this case has not yet been calibrated with the measurements. After calibration model and measurement agree quite well.

\subsection{Calculation of the amount of NCP from lidar measurements}

For estimating the NCP-concentration, the model Raman-signal, determined with the chl- $a$ and GS data, is calibrated with the measured Raman-signal in a clear water area where the NCP amount is assumed to be negligible. The difference between model calculations and measurements in other areas is proportional to the amount of NCP.

The chl- $a$ and GS concentrations measured by lidar are displayed in figures $6(a)$ and $(b)$. Figure $6(c)$ shows the Raman signals for flight track TR. The inverse of the Raman signal, the effective extinction coefficients for model and measurement are 
$\mathrm{Ch}-\mathrm{a}(\mu \mathrm{g} / \mathrm{l})$

(a)

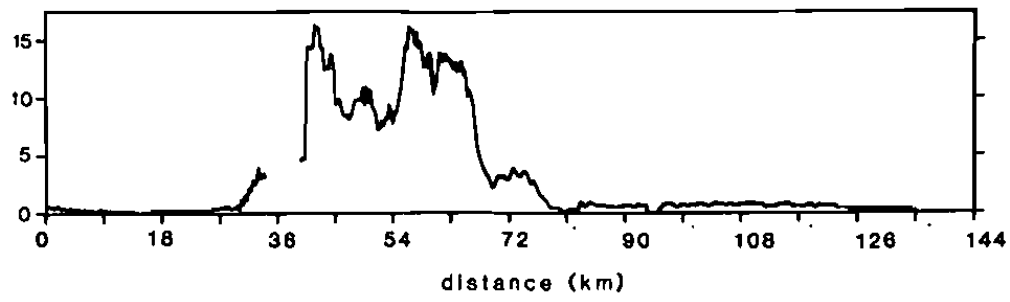

(b)

GS (mg/l)

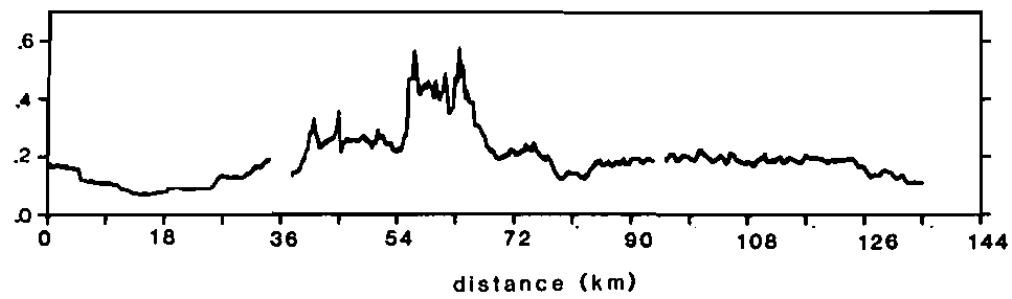

(c)

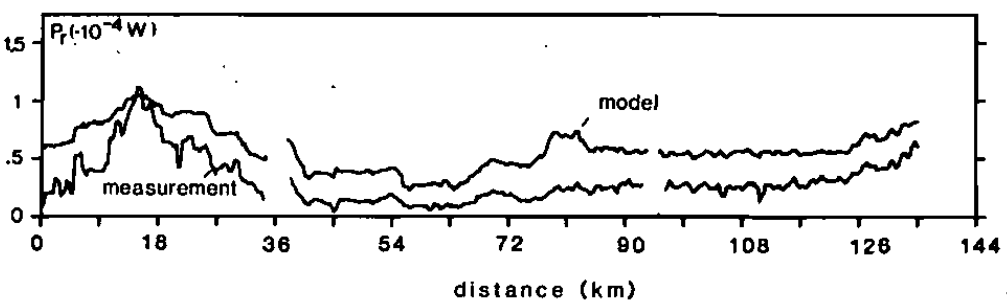

$(d) \mathrm{k}(308)+\mathrm{k}(344)\left(\mathrm{m}^{-1}\right)$

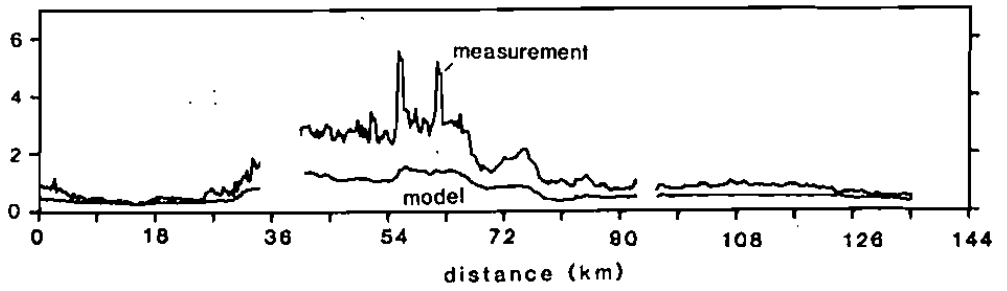

(e)

NCP (mg/l)

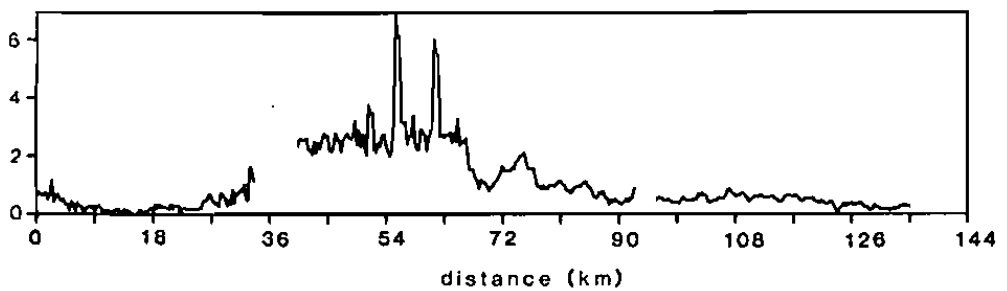

Figure 6. (a) Lidar chl- $a$ (a) and GS (b) concentrations for TR. Flight L30; date: 31 August 1984; time: 12.00 h. (c) Measured Raman signal and model Raman signal calculated with the chl- $a$ and GS concentrations from $(a)$ and $(b)$. The model Raman signal has been calibrated with the measured Raman signal in the clear water area at kilometre 15. The differences are a measure of NCP. $(d)$ Total effective extinction coefficient from Raman lidar measurements and effective extinction coefficient for chl-a and GS calculated with the lidar model. (e) Concentration of NCP derived from the difference of the measured and calculated extinction coefficient. 
(a)

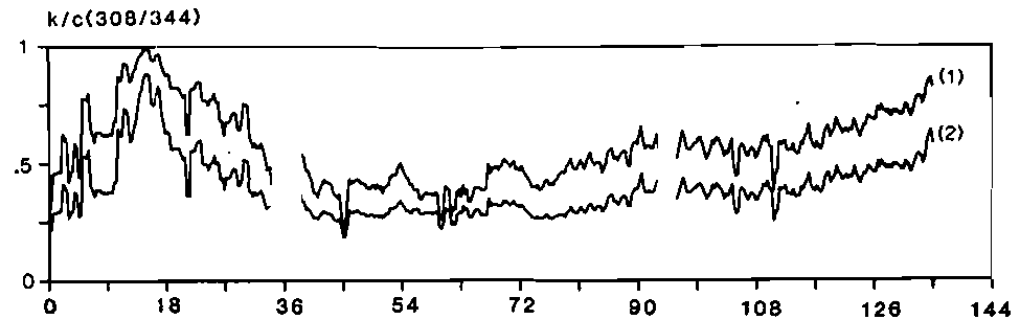

(b)

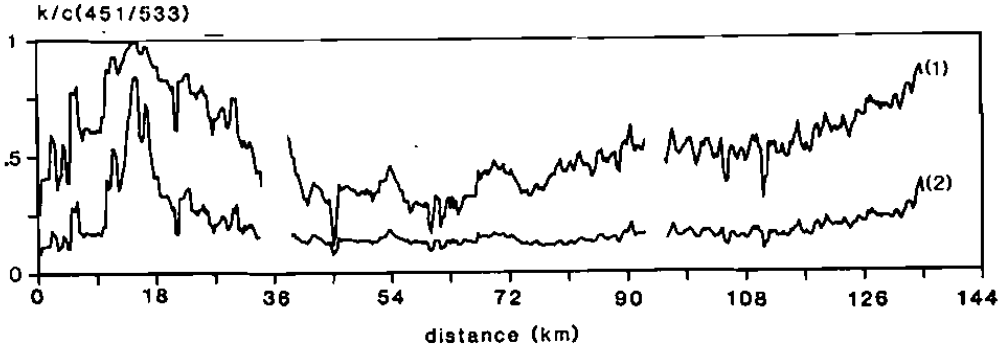

Figure 7. Ratio of the effective extinction coefficient $k$ (curve 1) and the diffuse extinction coefficient $K$ to the single scatter extinction coefficient $c$ (curve 2) for the Raman signal at $344 \mathrm{~nm}(a)$ and $533 \mathrm{~nm}(b)$.

shown in figure $6(d)$. The amount of NCP, calculated from the difference of the extinction coefficients, is shown in figure $6(e)$. The error in the retrieval of NCP depends on the quality of the retrieved chl- $a$ and GS concentration, the knowledge of the optical parameters of all three substances and the assumption that NCP is negligible in the clear water area, where the model Raman signal was calibrated.

\subsection{Multiple scattering in the northern Adriatic Sea}

Optically thick media like turbid ocean water will not be handled adequately by a single scattering lidar model approach. In order to show the impact of multiple scattering processes, the effective extinction coefficient $k$, the extinction coefficient $c$ and the diffuse extinction coefficient $K$ will now be compared. Figures $7(a)$ and $(b)$ display $k / c$ and $K / c$ in curves 1 and 2 respectively either for the Raman-signal, measured at $344 \mathrm{~nm}$ (figure $7(a)$ ) or for the Raman-signal, measured at $533 \mathrm{~nm}$ (figure $7(b))$. For the diffuse extinction coefficient the assumption $K=c\left(1-\omega_{0}\right)$ has been made, where $\omega_{0}$ is the single scattering albedo (ratio of scattering to extinction) of all oceanic constituents combined. From figure 7 it is obvious that only in very clear areas of the north-western Adriatic Sea the influence of multiple scattering of the lidar signal is small. Close to the River Po delta near kilometres 40 to 70 , multiple scattering is dominant. The high absorption by GS and water molecules in the near UV reduces the influence of multiple scattering, contrary to measurements in the green part of the spectrum.

\subsection{Calibration of satellite data}

The satellite-data used for the comparison with in situ measurements are measurements from the CZCS on board the NASA satellite Nimbus-7. The CZCS has been built for oceanographic applications especially in the visible spectrum. It has four spectral channels at $443 \mathrm{~nm}, 520 \mathrm{~nm}, 550 \mathrm{~nm}$ and $670 \mathrm{~nm}$ and one channel in the 
near infrared at $750 \mathrm{~nm}$. An additional channel in the thermal infrared window at $11.5 \mu \mathrm{m}$ for the measurement of thermal features at the ocean surface is also included (Hovis et al. 1980). The CZCS-image used for this study is from 29 August 1984. It was received at the University of Dundee, Scotland, and it was processed at the Institut für Meereskunde, Kiel, F.R. Germany.

The CZCS-channels $1-4$ were calibrated using the pre-flight calibration data by Hovis et al. (1980) and the sensitivity decay correction by Sturm (1985). For the correction of the atmospheric influence due to scattering and absorption it is necessary to separate the measured radiance $L_{\mathrm{T}}(\lambda)$ at the sensor into different parts:

$$
L_{\mathrm{T}}(\lambda)=L_{\mathrm{R}}(\lambda)+L_{\mathrm{A}}(\lambda)+t(\lambda) L_{\mathrm{w}}(\lambda)
$$

The main contributions to $L_{T}$ are the Rayleigh-scattering $L_{R}(\lambda)$ and the aerosol scattering $L_{\mathbf{A}}(\lambda)$, including the skylight reflected from the ocean surface. The water leaving radiance $L_{\mathrm{w}}(\lambda)$ is weighted with the diffuse transmission $t(\lambda)$ of the atmosphere. The use of $t(\lambda)$ is necessary as light from adjacent pixels is scattered into the actual field of view and increases $L_{\mathrm{w}}(\lambda)$. The determination of $L_{\mathrm{A}}(\lambda)$ is the main problem of the atmospheric correction procedure. According to Gordon (1978), the aerosol-radiance $L_{\mathrm{A}}(\lambda)$ at one wavelength is proportional to that at another wavelength, assuming the independence of the aerosol phase function. $L_{\mathrm{A}}(\lambda)$ can be determined at a distinct wavelength either by in situ measurements (Gordon 1978, Gordon and Clark 1981), or by the assumption, that no radiance leaves the water surface at channel 4 (clearest pixel-method). This assumption is valid only for open ocean waters with low pigment concentration. For turbid coastal waters with high concentrations of backscattering substances it is necessary to use an iterative method for the atmospheric correction (Smith and Wilson 1981). This method is based on a known relationship between the subsurface radiances for the 4 spectral bands of the CZCS. For the present study a special algorithm for the northern Adriatic Sea, developed by Sturm (1982), was used.

The comparison with underwater reflectance measurements was performed by converting the water-leaving radiance $L_{\mathrm{w}}(\lambda)$ into reflectance values $R(\lambda)$. The use of $R(\lambda)$ has the advantage, that it is independent to the extraterrestrial solar irradiance. The data were transformed into a geographical map allowing a direct comparison with the in situ measurements. The geographical accuracy is within \pm 2 pixels which corresponds to a distance of 1.7 to $2 \mathrm{~km}$ (Viehoff 1987).

\subsection{CZCS derived features of the northern Adriatic Sea}

In figures $8(a)-(d)$ the water-leaving radiances $L_{\mathrm{w}(\lambda)}$ for the CZCS channels 1-4 on 29 August 1984 for the northernmost of the Adriatic Sea are shown. Land surfaces and clouds are masked. The very high radiances east of some clouds-especially in channel 1 and 2-result from an overriding of the scanning radiometer when measuring the strong variation of upwelling radiances from the ocean and from clouds within a short time.

The most important feature in the images is the terrestrial input of NCP. The river runoff results in very high water-leaving radiances in the green and red part of the spectrum (channels 2-4) and very low radiances in the blue part of the spectrum (channel 1) due to the maxima in the absorption of chl- $a$ and GS. The river plume spreads off in a counter-clockwise orientation, forming an eddylike feature north-east of the delta. North of this feature clear water from the coast of Istria is flowing 
westward. A second cyclonic eddy is located east of the Venice Lagoon. These two eddies are separated by the relatively clear water zone south-east of Chioggia, clearly seen from the channel 3 image. Similar features were also observed in some images from summer 1982 (Nykjaer et al. 1983). The eddylike plume has also been depicted from hydrographic measurements (Franco et al. 1982, Malanotte-Rizzoli and Bergamasco 1983) and remote sensing studies with the CZCS during other years (Nykjaer et al. 1983, Barale et al. 1984). A small band of highly turbid water follows the northern coast line, a result of sediment transport and erosion in the sea. The width of this feature is smaller than similar structures observed in April 1979 (Barale et al. 1984). A second feature of highly turbid water is located south of the zonal cloudband along the Italian coast down to $43^{\circ} \mathrm{N}$. The difference in the optical properties between these turbid coastal waters and the Po river plume water is mainly caused by the high amount of GS in the river water. The strong GS absorption at $440 \mathrm{~nm}$ lowers the water-leaving radiance at this wavelength.

All these hydrographic features can be distinguished more easily using the visible channels of the CZCS than using for example the infrared data from the NOAAAVHRR as underlined by a comparison of AVHRR channel $4(11.0 \mu \mathrm{m})$ brightness temperatures (figure $8(e)$ ) with the different CZCS-channels (figure $8(a)-(d)$ ). At the time of the NOAA satellite overpass on 29 September 1984 a high pressure cell, located over Northern Italy with low surface wind velocities, leads to a decoupling of the ocean top layer from the underlying mixed layer of the preceding night. This can be seen clearly at the south-eastern part of figure $8(e)$ where a local very warm area is shown with a temperature rise of more than $2 \operatorname{deg} \mathrm{K}$ compared to the surrounding areas. The eddylike turbidity structures in the River Po outflow are masked in the temperature image by the warmed top layer.

\subsection{Intercomparison of CZCS and radiometer measurements}

Surface reflectance values at the hydrographic stations of figure 1 are now compared to satellite derived values in figures $9(a)-(d)$. The CZCS reflectances are averages over $3 \times 3$ pixel in order to reduce the possible uncertainties due to the navigation error of the satellite data. There is a coarse correlation between both measurements except for the reflectance at $440 \mathrm{~nm}$. No dependence of the differences on the time interval between the measurements could be observed. The underestimation of reflectance of CZCS channel 1 data is probably a result of the high amount of GS in the river runoff.

The reflectance ratio $R(443) / R(550)$ in figure 10 shows the turbidity features as discussed for the water-leaving radiances, however, the values for the river plume and the turbid coastal waters now have the same order of magnitude. The comparison with the in situ chl- $a$ concentration in $\mu \mathrm{g} / 1$ gives a relation of $\log$ chl- $a=(-0.44 \mu \mathrm{g} / 1-1.87 \mu \mathrm{g} / \mathrm{l}) \cdot \log (\mathrm{R}(443) / \mathrm{R}(550))$ with $r^{2}=0.87$. This algorithm is close to the algorithm by Viollier and Sturm (1984) for the same area. The values of $r^{2}$ for analogous algorithms for GS and NCP are 0.93 and 0.73 .

\subsection{Intercomparison of CZCS and lidar measurements}

Since a specific goal of this paper is the use of lidar data for the calibration of satellite data, the measurements of the CZCS from 29 August 1984 have been compared with the lidar measurements for flight track TR. The track contains 132 satellite pixels with a horizontal resolution of $1 \mathrm{~km}$. Unfortunately the geographical coordinates of the lidar system are only known at the start and end of the track. In 


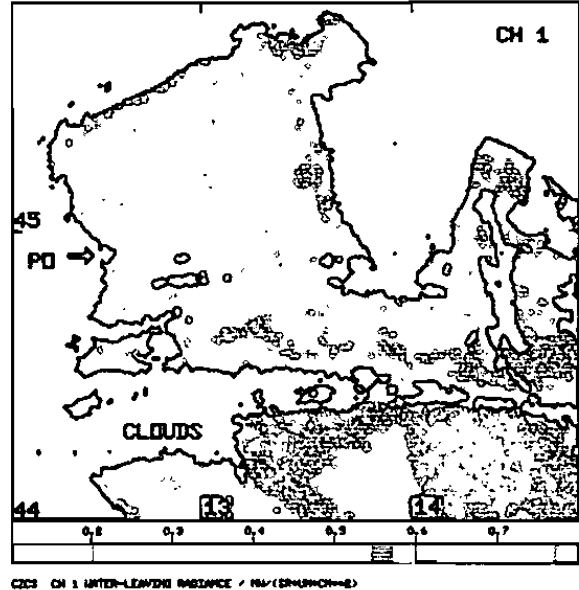

Figure $8(a)$.

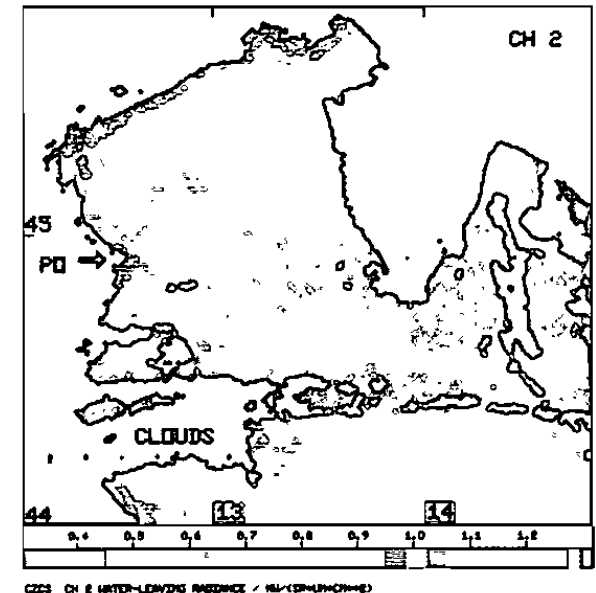

Figure $8(h)$.

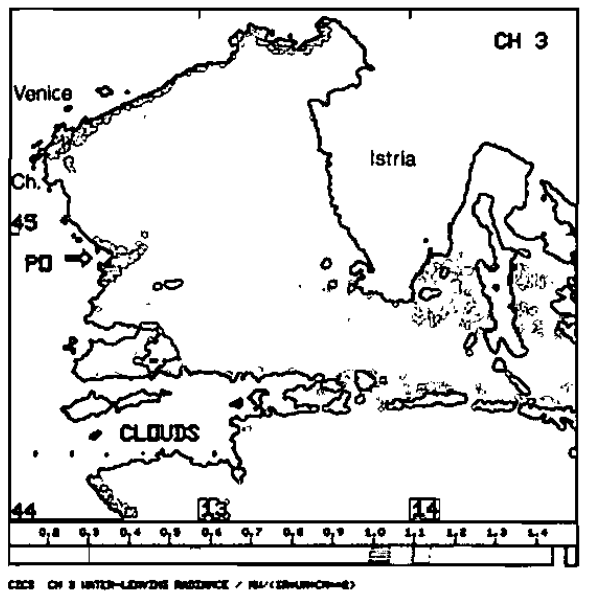

Figure $8(c)$.

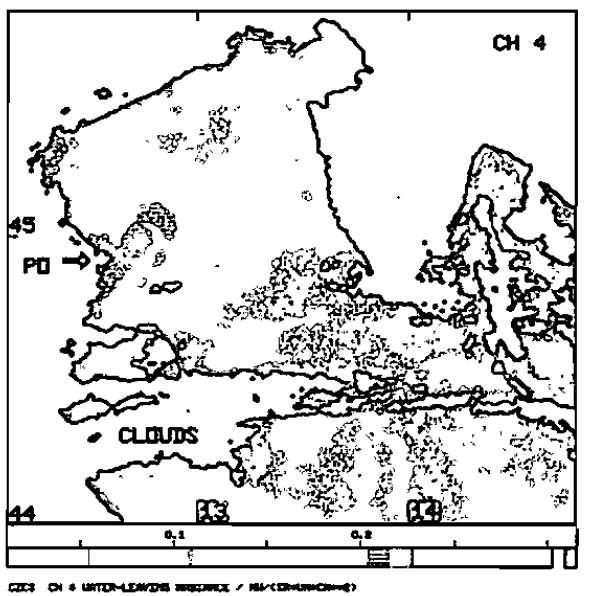

Figure $8(d)$. 


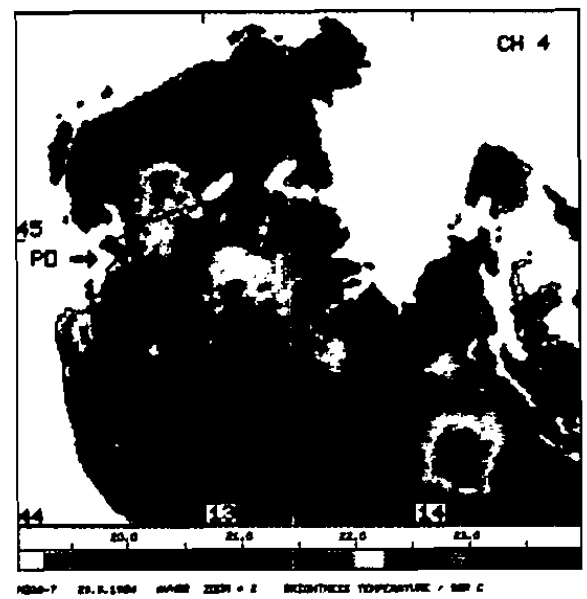

Figure 8(e).

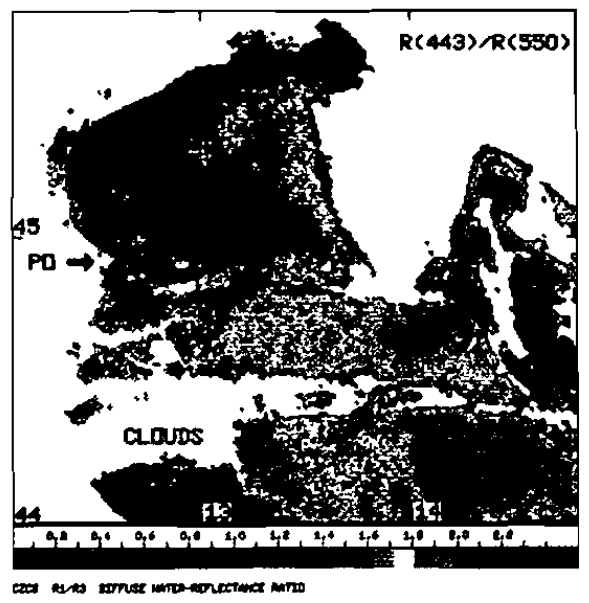

Figure 10.

Figure 8. Waterleaving radiance for $440 \mathrm{~nm}(a), 520 \mathrm{~nm}(b), 550(c)$ and $670 \mathrm{~nm}(d)$, derived from the CZCS data for the CZCS data for the northern Adriatic sea, Date: 29 August 1984; time: $12.00 \mathrm{~h}$. (e) Brightness temperature derived from AVHRR data (NOAA-7) for the northern Adriatic Sea. Date: 29 August 1984; time: $12.00 \mathrm{~h}$.

Figure 10. Reflectance ratio $R(443) / R(550)$, derived from the CZCS data for the northern Adriatic Sea.

order to partly compensate for uncertainties in the position of the airplane and the better spatial resolution of the lidar, arithmetic means of three CZCS pixels have been compared with the lidar measurements. The pixel on the lidar flight track and the next neighbour west and east from the track were averaged. Three lidar measurements along the track were also averaged to reach a horizontal resolution in north-south direction comparable to the CZCS resolution. After averaging, the lidar data are mean values over an area $750 \mathrm{~m}$ long and of $1 \mathrm{~m}$ wide. Figures $11(a)$ and $(b)$ show chl- $a$ concentrations measured by the OLS and corresponding CZCS radiance ratios. Both sensors capture the increase in chl- $a$ concentration due to river plumes. From the lidar measurements two chl- $a$ maxima with concentrations of $10-15 \mu \mathrm{g} / \mathrm{l}$ can be seen. Peak 1 corresponds to the outflow from the lagoon of Venice with a width of $8 \mathrm{~km}$ and peak 2 to the plume of the River Po. The latter peak is about twice as broad as peak 1 at this longitude.

The CZCS measurements show a higher variation of the blue-green ratio and the two maxima in the OLS data can not be separated. The reason is the interference of the three substances chl- $a$, GS and NCP, which all influence the blue-green ratio and which are not highly correlated. Figure $11(b)$ points to the failure of blue-green ratio techniques for chl- $a$ estimates in case 2 waters.

A good agreement between passive and active measurements has been found by Hoge et al. (1986 a, b), using a lidar and a radiometer on the same airplane. Upwelling radiances and lidar data were collected alternating using the same telescope. The CZCS data have been compared with radiative transfer calculations, too, using chl- $a$, GS and NCP concentrations from the lidar measurements. The mean blue-green 
ratio calculated with the ocean-atmosphere model is 3 , which is small compared to the mean CZCS value of 5 (see figure $11(b)$ ). Reasons for the difference might be (a) wrong assumptions for the optical properties of chl- $a$, GS and NCP, (b) an inaccurate atmospheric correction for the CZCS data due to horizontal variations of the aerosol type, and (c) lack in the knowledge of the sensitivity loss of the CZCS channels.

\section{Conclusions}

The ADRIA'84 experiment was ideally suited for comparison of different remote sensing techniques trying to measure sea water constituents influencing the water

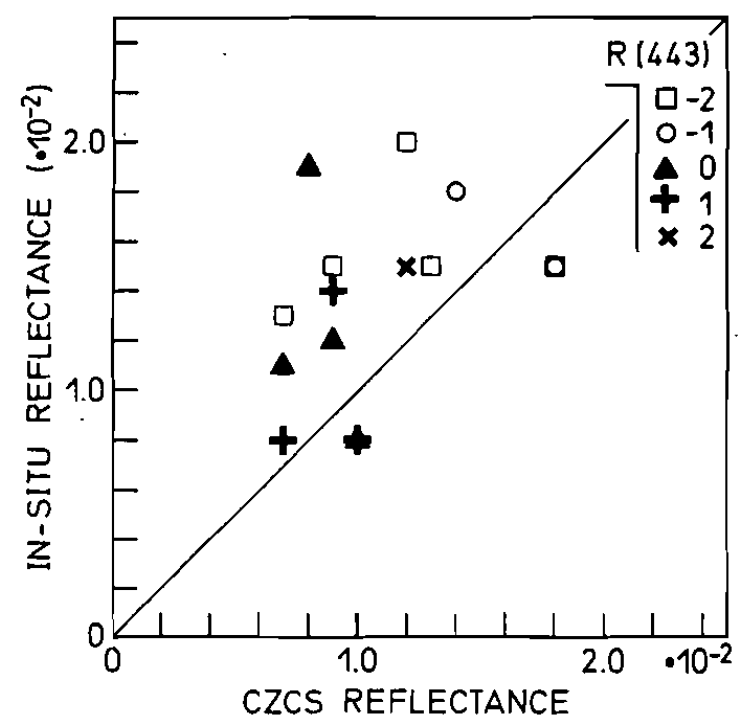

(a)

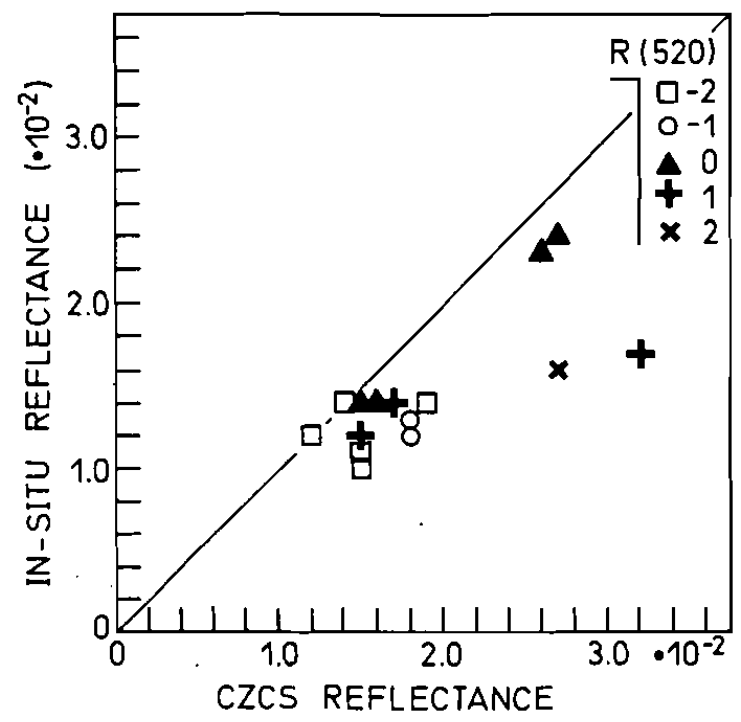

(b) 


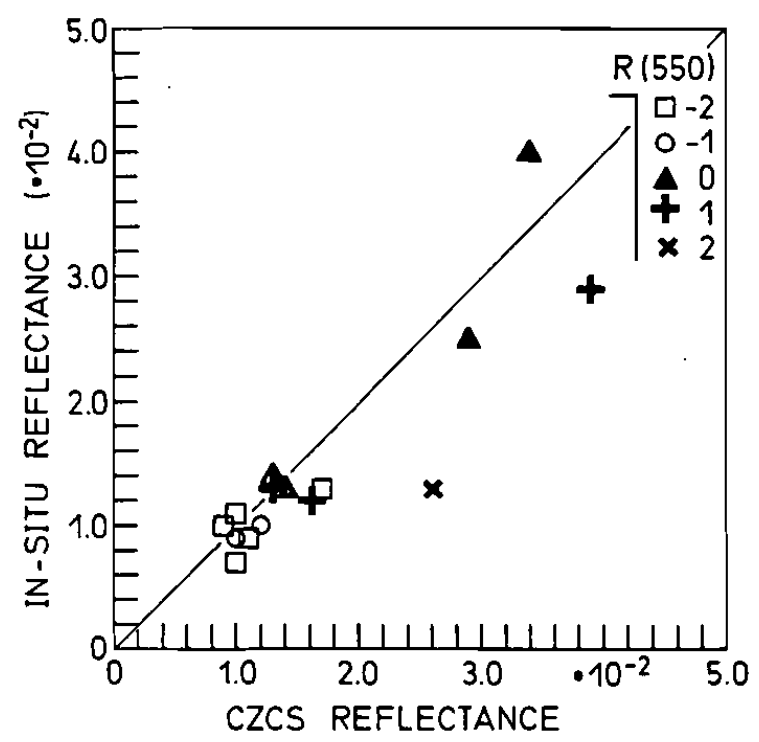

(c)

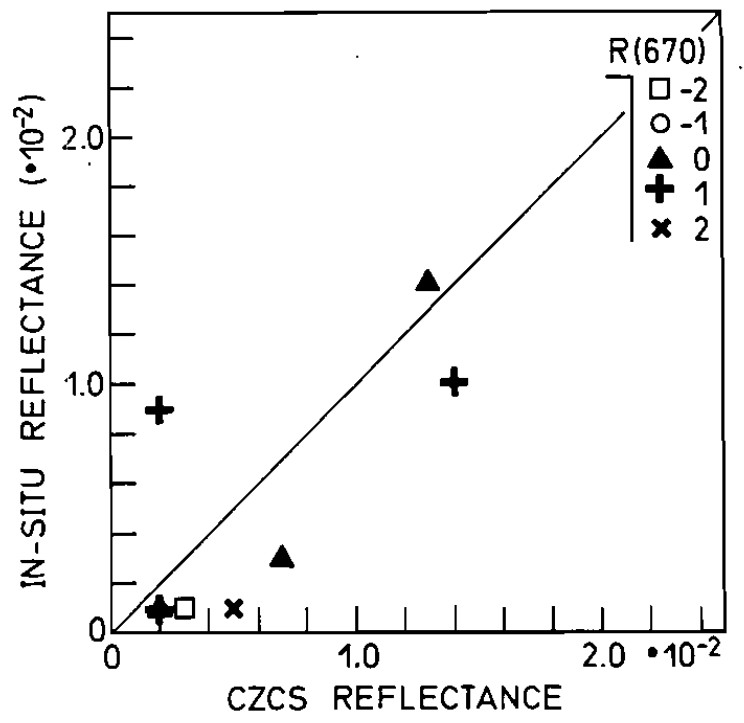

(d)

Figure 9. (a) Comparison between diffuse water reflectances at (a) $440 \mathrm{~nm},(b) 520 \mathrm{~nm},(c)$ $550 \mathrm{~nm}$ and $(d) 670 \mathrm{~nm}$ derived from satellite data (R(CZCS)) and in situ measurements ( $\mathrm{R}($ in situ $)$ ). The time interval between measurements of $\mathrm{R}(\mathrm{CZCS})$ and $\mathrm{R}($ in situ $)$ in hours is indicated by different symbols. 
(a) Chl-a

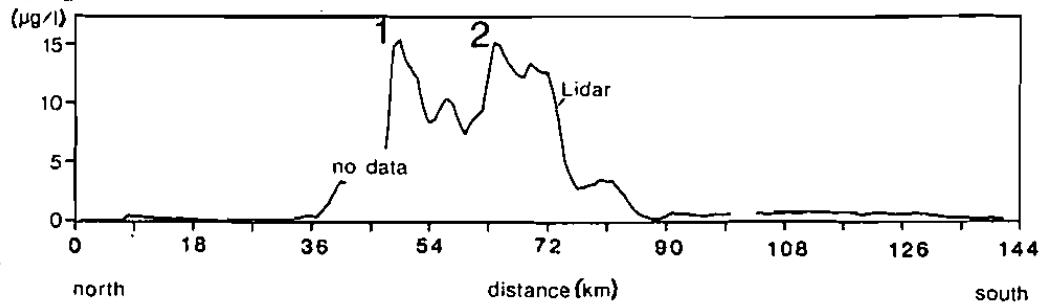

(b)

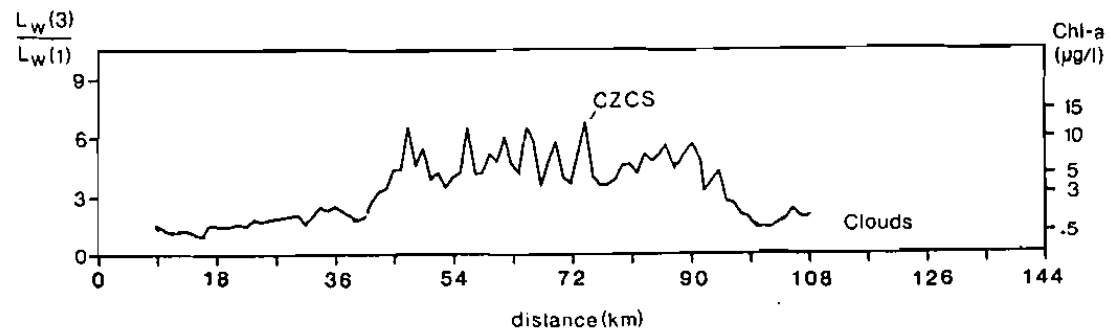

Figure 11. Chl- $a$ concentration derived from $(a)$ lidar and $(b)$ CZCS measurements. Flightline TR; date: 29 August 1984; time: $12.00 \mathrm{~h}$. Peaks 1 and 2 in the chl- $a$ curve are discussed in the text.

colour in coastal areas. A quite high density of in situ measurements from ships or buoys and the good weather conditions during the experiment allowed the validation of satellite and airborne lidar measurements by in situ measurements. We have validated the radiative transfer model with the measured upwelling irradiance data just below sea surface, calibrated the airborne ocean lidar with in situ measurements of oceanic constituents, compared model calculations with satellite data, intercompared different satellites and tried to compare lidar measurements of sea water constituents with those from the CZCS onboard the Nimbus 7 satellite. Our main results are:

(1) OLS for chl-a and GS determination. The airborne oceanic lidar of the University of Oldenburg is suitable to detect small scale variations of chl- $a$ and GS by measuring the depth integrated fluorescence due to these constituents. If the fluorescence measurements are normalized by the Raman-signal, and calibrated by in situ measurements, even the fluorescence efficiencies of chl- $a$ and GS can be calculated.

(2) Nonchlorophyllous particle extinction coefficient from lidar measurements. The extinction coefficient of NCP (the seston) can be determined using chl- $a$ and GS values from fluorescence measurements as well as the Raman-scattering of water molecules. If the specific extinction coefficients of chl- $a$ and GS and the single scattering albedo of chl- $a$ containing algae are known, a model Raman-signal can be calculated. This signal is then calibrated with the measured Raman-signal in the area with the clearest waters. The difference of the inversion of both Raman-signals-one only accounting for chl- $a$ and GS-is the effective extinction coefficient of NCP. The error in retrieving the amount of NCP mainly depends on the knowledge of the specific extinction coefficients of chl- $a$ and GS. Also the assumption that the amount of NCP at the calibration point can be neglected, contributes to the error.

(3) Intercomparison of lidar and satellite data. The comparison between the CZCS and the OLS ch- $a$ measurements shows, that different scales are resolved by the instruments. The main problem in using lidar chl- $a$ measurements for calibrating 
satellite data is the variability of the fluorescence efficiency. In general it is still necessary to calibrate the lidar data with in situ measurements from time to time.

(4) Mesoscale structures from ocean turbidity or ocean temperature data. A comparison between the AVHRR sea surface temperature and the CZCS measurements of the Adriatic sea was made. It shows, that mesoscale structures in the ocean are much better indicated by measurements in the visible than in the infrared. During high pressure periods with a cloudless sky and low surface winds, the warming of the ocean top layer masks the mesoscale structures at the surface.

(5) The failure of simple algorithms for chl-a content in turbid coastal waters. As already investigated by theoretical studies (Schmitz-Peiffer and Graßl 1990), the measurements show, that the CZCS chl- $a$ concentration, derived by a blue-green algorithm in coastal waters is influenced by GS and NCP, too. In the future, these problems will be solved by spaceborne sensors, measuring the sun-induced chl- $a$ fluorescence.

\section{Acknowledgments}

Many colleagues have helped us. We gratefully acknowledge that Jürgen Fischer from the GKSS Rescarch Centre, Geesthacht, F.R. Germany, made his atmosphereocean model available to us. The OLS measurements were provided to us by Dorothee Diebel, Kurt Günther and Rainer Reuter from the Department of Physics, University of Oldenburg, F.R. Germany. Peter Schlittenhardt and Boris Sturm from the Joint Research Centre, Ispra, Italy, provided us with the ship and buoy measurements. Roland Doerffer from the GKSS gave us the underwater radiometer used on RV Bannock during the ADRIA'84 campaign and helped us during the evaluation of the data at the GKSS. The work was financially supported by the Bundesministerium für Forschung und Technologie, Bonn, and by the GKSS.

\section{References}

Barale, V., Rizzoli, P. M., and Henderschott, M. C., 1984, Remote sensing of the surface dynamics of the Adriatic Sea. Deep Sea Research, 31, 1433-1459.

Browell, E. V., 1977, Analysis of laser fluorosensor systems for remote algae detection and quantification; NASA Technical Note D-8447, NASA Langley Research Center Hampton.

Diebel-Langohr, D., Hengstermann, T., and Reuter, R., 1985, Laser remote sensing of the marine environment: recent results obtained with the oceanographic lidar system. Proceedings of the 3rd International Colloquium on Spectral Signatures of Objects in Remote Sensing held in Les Arcs, France, on 16-20 December 1985, ESA SP-247 (Paris: European Space Agency), pp. 267-272.

Diebel-Langohr, D., HengstermanN, T., and Reuter, R., 1986, Identification of hydrographic fronts by airborne lidar measurements of Gelbstoff distributions. In Marine Interfaces Ecohydrodynamics, edited by J. C. J. Nihoul (Amsterdam: Elsevier Scientific Publishing Company), pp. 569-590.

FisCHER, J., 1983, Fernerkundung von Schwebstoffen im Ozean; Hamburger Geophysikalische Einzelschriften, Reihe B, Heft 65, External Report (University of Hamburg).

FISChER, J., DOERFFER, R., and Grabl, H., 1986, Factor analysis of multispectral radiances over coastal and open ocean water based on radiative transfer calculations. Applied Optics, 25, 448-456.

FisCHER, J., and GrABL, H., 1984, Radiative transfer in an atmosphere-ocean system; An azimuthally dependent Matrix-Operator-approach. Applied Optics, 23, 1032-1039.

Franco, P., Jeffic, L., Malanotte-Rizzoli, P., Michelato, A., and Orlic, M., 1982, Descriptive model of the northern Adriatic sea. Oceanologica Acta, 5, 379-389.

GoRDoN, H. R., 1978, Removal of atmospheric effects from satellite imagery of the oceans. Applied Optics, 17, 1631-1636. 
GoRDON, H. R., 1982, Interpretation of airborne oceanic lidar: effects of multiple scattering. Applied Optics, 16, 2996-3001.

Góndon, H. R., and ClaRK, D. K., 1981, Clear water radiances for atmospheric correction of coastal zone color scanner imagery. Applied Optics, 20, 4175-4180.

GowER, J. F. R., 1981, Use of the in vivo fluorescence line at $685 \mathrm{~nm}$ for remote sensing surveys of surface Chlorophyll-a. In Oceanography from Space, edited by J. F. R. Gower (New York, London: Plenum Press), pp. 329-338.

Hoge, F. E., Berry, R. E., and SwIFT, R. N., 1986, Active-passive airborne ocean color measurements: 1: instrumentation. Applied Optics, 25, 39-47.

Hoge, F. E., SwIFT, R. N., and YUNGel, J. K., 1986, Active-passive airborne ocean color measurements. 2: application. Applied Optics, 25, 48-57.

HojersLev, N. K., 1979, On the origin of yellow substance in the marine environment. In Studies in Physical Oceanography (Kobenhavns Universitet: Institut for Fysisk, Oceanografi), p. 192.

Hovis, W. A., Clark, D. K., Anderson, F., Austin, R. W., Wilson, W. H., Baker, E. T., Ball, D., Gordon, H. R., Mueller, J. L., El SAyed, S. Y., Sturm, B., Wrigley, R. C., and YENTSCH, C. S., 1980, Nimbus 7 Coastal Zone Color Scanner: system description and initial imagery. Science, 210, 60-63.

Malanotte-Rizzoli, P., and Bergamasco, 1983, The dynamics of the coastal region of the northern Adriatic Sea. Journal of Physical Oceanography, 13, 1105-1130.

Nykjaer, L., SChlitTenhardt, P., and Sturm, B., 1983, Qualitative and quantitative interpretation of ocean color Nimbus-7 CZCS imagery of the northern Adriatic Sea from May to September 1982. Report No. S.A./I. 05E2.84.05, Remote Sensing Programme, Joint Research Centre, Ispra, Italy.

SChlittenhardt, P. M., 1986, ADRIA'84 Data Catalogue. Report No. 1.05.E2.85.230, Commission of the European Communities, Joint Research Centre, Ispra, Italy.

SChlüssili, P., and Grabl, H., 1984, Transmission of the oceanic Chlorophyll-a fluorescence to the top of the atmosphere. Deutsche Hydrographische Zeitschrift, 37, 58-69.

SChmitz-Peiffer, A., 1986, Fernerkundung ozeanischer Schwebstoffe mit flugzeuggetragenen Lasern und Satellitenradiometern, GKSS External Report No. 86/E/49 (available from GKSS, D-2045 Geeshacht, F.R. Germany).

SChMitz-Peiffer, A., and GraBL, H., 1990, Remote sensing of coastal waters by airborne lidar and satellite radiometer. Part 1: A model study. International Journal of Remote Sensing, 11, 2163-2184.

SMITH, R. C., and WILSON, W. H., 1981, Ship and satellite bio-optical research in the California bight. In Oceanography from Space, edited by J. F. R. Gower (New York: Plenum Press), pp. 281-294.

STURM, B., 1982, Developments in CZCS data evaluation at JRC Ispra during 1981. Internal Report, 18. NET, January 1982.

STURM, B., 1985, CZCS sensitivity decay study. Internal Report, Joint Research Centre, Ispra, Italy.

VıвноFF, T., 1987, Bestimmung mesoskaliger Variabilitäten der Oberflächentemperatur und der Attenuation im Nordatlantik aus Satellitenmessungen, Berichte aus dem Institut für Mecreskunde No. 162 (available from Institut für Meereskunde, Düsternbrooker Weg 20, D-2300 Kiel 1, F.R. Germany).

Viollier, M., and STURM, B., 1984, CZCS data analysis in turbid coastal water. Journal of Geophysical Research, 89, 4977-4985. 